\title{
Skryfprobleme met chemieterme (vervolg)
}

\author{
D.F. Louw
}

WNNR, Posbus 395, Pretoria 0001

\section{Afrikaanse benamings vir die -onic acids}

Met die hersiening van die Chemiewoordeboek (1968) is onder andere aandag geskenk aan die name van 'n groep chemiese verbindings waaraan gesamentlik die Engelse benaming -onic acids gegee kan word, ondanks die feit dat die groep verbindings in chemiese aard 'n breë verskeidenheid behels. Opvallend genoeg is die Afrikaanse ekwivalente benamings nie so eenvormig nie: daar is minstens twee duidelik onderskeibare kategorieë, naamlik dié met die uitgang -oonsuur en daarnaas dié met -onsuur, benewens 'n beperkte getal "afwykende" benamings. Ter vergelyking word in die meegaande termelys ook die Duitse benamings ${ }^{1}$ gegee, waaruit blyk dat die uitgang -onsäure konsekwent gebruiklik is, met die uitsondering van Kohlensäure.

\author{
Engels \\ arsonic acid \\ brucinonic acid \\ camphononic acid \\ carbonic acid \\ chelidonic acid \\ crotonic acid \\ gluconic acid \\ loiponic acid \\ malonic acid \\ naphthionic acid \\ paraconic acid \\ pinonic acid \\ sulphonic acid \\ thionic acid \\ uronic acid
}
Afrikaans
arsoonsuur
brusinoonsuur
kamfonoonsuur
koolsuur
chelidoniensuur
krotonsuur
glukonsuur
loiponsuur
malonsuur
naftioonsuur
parakonsuur
pinoonsuur
sulfoonsuur
tioonsuur
uronsuur

Hoewel dit nêrens so geformuleer is nie, wil dit tog voorkom asof ' $n$ bepaalde (miskien toevallige) stelsel waarby die chemiese aard van verbindings in ag geneem is, wel as grondslag gedien het vir 1968 se Chemiewoordeboek. Dit blyk naamlik dat die Engelse benaming -onic acid in dié uitgawe die volgende onderskeibare groepe chemiese verbindings dek en dat daar vir elke groep 'n betreklik konsekwente Afrikaanse benamingswyse toegepas is:-

(a) Suikersure

Dié groep -onic acids is oksidasieprodukte van koolhidrate en het almal die chemiese formule HOOC $\cdot(\mathrm{CHOH})_{\mathrm{n}} \cdot \mathrm{CH}_{2} \mathrm{OH}$. In dié groep, wat sedert 1968 in Afrikaans -onsure geword het, word verbindings soos glukonsuur, mannonsuur,

Duits
Arsonsäure
Brucinonsäure
Camphononsäure
Kohlensäure
Chelidonsäure
Crotonsäure
Gluconsäure
Loiponsäure
Malonsäure
Naphthionsäure
Parakonsäure
Pinonsäure
Sulphonsäure
Thionsäure
Uronsäure

mannoheptonsuur, liksonsuur, nonulosonsuur en xilonsuur ingesluit. Geriefshalwe kan hierby die -uronic acids, wat die formule HOOC. $(\mathrm{CHOH})_{\mathrm{n}}$. CHO het (soos glukuronsuur, mannuronsuur, penturonsuur en ander -uronsure), ingesluit word, asook verbindings van die tipe HOOC. $(\mathrm{CHOH})_{n} \cdot \mathrm{COOH}$ (soos tartronsuur). Dit is opvallend dat die Chemiewoordeboek egter hexonic acid lactone met heksoonsuurlaktoon vertaal en dus in stryd met die stelsel die affiks oon-gebruik waar die laktoon sy herkoms het in 'n suikersuur wat heksonsuur $\mathrm{HOOC} \cdot(\mathrm{CHOH})_{4}$. $\mathrm{CH}_{2} \mathrm{OH}$ genoem sou gewees het. Die laktoonsuur paraconic acid is egter wel met parakonsuur vertaal, sodat dit nie lyk of dit die -oon in laktoon was wat die Afrikaanse skryfvorm beinvloed het nie. Die Chemiewoordeboek gee ook nog mannoheptoonsuur vir die suikersuur mannoheptonic acid $\mathrm{HOOC} \cdot(\mathrm{CHOH})_{5} \cdot \mathrm{CH}_{2} \mathrm{OH}$, wat volgens die skryfreëls van 1968 in Afrikaans eintlik met 'n heptonsuur genoem moes gewees het. 
(b) Ketosure

Teenoor die voorgenoemde groep verbindings, waarvan sommiges aldehiedgroepe $(-\mathrm{CHO})$ bevat, staan die ketosure (wat dus die ketoongroep $=\mathrm{C}=\mathrm{O}$ bevat) en almal reeds sedert 1955 só benoem word dat die affiks -oon- in die naam voorkom. Dit is byvoorbeeld die geval met brusinoonsuur, kamfonoonsuur, foroonsuur en pinoonsuur.

Daar moet gelet word op die feit dat laktoonsure soos itakonsuur, parakonsuur en tetronsuur nie by dié groep gereken moet word nie. Hulle $\mathrm{CO}$-groepe is nie ketogroepe nie en hulle benamings vertoon sedert 1968 almal die affiks -on-, terwyl vroeër wel -oon-geskryf is. Dit is egter vreemd dat 'n verbinding soos siklopentaanpentoon in die Chemiewoordeboek (1968) tog die benaming leukonsuur gekry het, want met sy vyf karbonielgroepe sou leukoonsuur seker verkieslik gewees het - soos dit in 1955 se Lys Skeikundige Terme geskryf is. In 1968 is sedanonic acid met sedanonsuur vertaal, terwyl dié ketoverbinding eintlik sedanoonsuur genoem behoort te gewees het. Eweneens behoort pyromeconic acid, wat 'n hidroksipiranoon met swak suureienskappe is, dalk liewer in Afrikaans piromekoonsuur genoem te gewees het, en nie piromekonsuur nie, soos dit in die Chemiewoordeboek staan. Phthalonic acid is 'n karboksibensoïelmieresuur, wat 'n fenielhidrasoon vorm soos 'n tipiese ketoon en dit behoort volgens die 1968-stelsel in Afrikaans nie ftalonsuur nie, maar ftaloonsuur genoem te gewees het, soos dit trouens in 1955 geskryf is.

(c) Organiese sure met arseen, boor en fosfor

Die benamings arsoonsuur en fosfoonsuur geld reeds sedert 1955 onderskeidelik as Afrikaanse ekwivalente vir arsonic acid en phosphonic acid. Dit verwys na verbindings van die vorm $\mathrm{RAsO}(\mathrm{OH})_{2}$ en $\mathrm{RPO}(\mathrm{OH})_{2}$. $\mathrm{Na}$ analogie hiervan sal boronic acid $\left(\mathrm{R}_{2} \mathrm{BOH}\right)$ in Afrikaans met boroonsuur vertaal word en telluronic acid ( $\mathrm{RTeO}_{2}(\mathrm{OH})$ ) met telluroonsuur. Op soortgelyke wyse kry ons ook karboonsuur as minder gebruiklike benaming vir 'n karboksielsuur $\mathrm{RCO}(\mathrm{OH})$. Dan behoort 'n nitronic acid $(=\mathrm{NO}(\mathrm{OH}))$ in Afrikaans vermoedelik nitroonsuur genoem te word en nie nitronsuur soos dit in die Chemiewoordeboek vertaal is nie. Terloops, in Duits word Arsonsäure, Boronsäure, Phosphonsäure en Nitronsäure geskryf.

(d) Organiese sure met swael

Die bekendste sure in dié groep is seker die sulphonic acids (met $-\mathrm{SO}_{3} \mathrm{H}$ ) wat in Afrikaans as sulfoonsure bekend staan. Verbindings soos metioon-, etioon- en naftioonsuur het almal een of meer $\mathrm{SO}_{3} \mathrm{H}$-groepe en die Afrikaanse benamingspatroon met -oon- bly konsekwent. Die vebinding myronic acid is van 'n tiosuiker afgelei en omdat dit die groep - $\mathrm{OSO}_{3} \mathrm{H}$ bevat, word dit in Afrikaans miroonsuur genoem. Verder is daar die thionic acids (met $=\mathrm{SOH}$, soos in carbothionic acid) wat die Afrikaanse ekwivalent tioonsure het.

(e) Ander mono- en dibasiese -onic acids

Die eenvoudigste verbinding in die groep is $\mathrm{H}_{2} \mathrm{CO}_{3}$ wat in Engels carbonic acid genoem word. In Afrikaans word dit koolsuur genoem (Duits: Kohlensäure), 'n benaming wat dus glad nie by die normale patroon van -onsure en oonsure inpas nie.

Die ander mono- en dibasiese -onic acids is in Duits almal van die -on-vorm (soos Crotonsäure, Citraconsäure, Malonsäure, Mesaconsäure en Uvitonsäure). Hulle Afrikaanse ekwivalente word almal ook met -on- geskryf: krotonsuur, sitrakonsuur, malonsuur, mesakonsuur en uvitonsuur.

By die verafrikaansing van chelidonic acid (die benaming vir 'n piroondikarboksielsuur) het egter iets vreemds in die Chemiewoordeboek na vore gekom. Terwyl die Duitse ekwivalent Chelidonsäure is, en dit in Afrikaans chelidoonsuur genoem behoort te gewees het (soos dit trouens in 1955 se Lys Skeikundige Terme geskryf is), is chelidoniensuur in 1968 sonder enige verduideliking opgeneem. Hierteenoor is meconic acid (ook bekend as oxychelidonic acid), wat in Duits Mekonsäure genoem word, in Afrikaans met mekonsuur vertaal. Gewoonlik word -onin(e), soos dit in digitonin en cusconine voorkom, in Afrikaans met -onien vertaal.

\section{SAMEVATTING}

Dit lyk asof daar by die saamstel van die Chemiewoordeboek in 1968 besluit is om by die vertaling in Afrikaans van benamings waarin -onic acid voorkom, twee beginsels te laat geld, naamlik -

(a) die affiks -oon-word gebruik by sure met swael en ander anorganiese elemente soos arseen, boor en fosfor, asook by ketosure;

(b) in alle ander gevalle word -on-gebruik.

Met die toepassing van dié skryfbeginsels is die benamingsbeleid van 1955, toe deurgaans -oon-gebruik is (krotonsuur was toe oënskynlik 'n uitsondering, maar dit is toe waarskynlik so geskryf omdat die eerste lettergreep beklemtoon is), sonder enige toeligting of motivering gewysig. Saam met die nuwe skryfbeginsels het daar egter in 1968 'n paar "foutiewe" Afrikaanse vertalings voorgekom, vermoedelik vanweë mistastings oor die presiese chemiese aard van die betrokke verbindings. Sulke haakplekke/foute het veral by laktone en verbindings met keto-enolisomerie na vore getree. Dit wil dus voorkom asof die genoemde twee reëls van 1968 nie in alle omstandighede bevredigend toegepas kon word nie en meer probleme geskep het as wat oënskynlik met die wysiging van 1955 se skryfbeleid voorsien is.

'n Terugkeer na 'n konsekwente -oon-vorm (soos in 1955) by die Afrikaanse vertaling van benamings 
vir -onic acids kan aanbeveel word. Daardeur sal 'n grotendeels eenvormige skryfvorm verkry word soos by Engels (met -onic) en Duits (met -on), asook 'n onweerlegbare vereenvoudiging wat die reël en sy toepassing betref. Die beginsel behoort egter steeds gehandhaaf te word dat die onbeklemtoonde lettergreep in Afrikaans -on-geskryf word (soos by proton), teenoor -oon- (soos by ketoon, laktoon en sulfoon) wanneer dié lettergreep wel klem dra. So 'n vereenvoudiging lyk absoluut wenslik by die huidige hersiening van die Chemiewoordeboek en sal heelwat vertaalprobleme oplos soos uit die volgende voorbeelde sal blyk:-

* Oxonic acid: Die vebinding staan in Engels ook as allantoxanic acid bekend en dit bevat twee $\mathrm{CO}$ groepe in 'n sesring (saam met drie stikstof- en twee koolstofatome). Die CO-groepe is dus nie ketonies van aard nie. In 1955 sou die Afrikaanse ekwivalent oksoonsuur gewees het, wat in 1968 tot oksonsuur gewysig sou gewees het. Volgens die nuwe reëls wat hierbo voorgestel is, sal weer $o k$ soonsuur geskryf word, maar werklike kennis oor die chemiese aard van die CO-groepe is nie by die besluit ter sprake nie.

* Picrolonic acid: Dieselfde argumentering sal gevolg word om nou in Afrikaans pikroloonsuur te skryf (soos in 1955), terwyl in 1968 besluit is dat die pirasolinoonverbinding as pikrolonsuur bekend moet staan. Dit is dus nie ter sake of die COgroep in die pirasoloonring wel of nie ketonies van aard is nie.

* Tetronic acid: Hierdie laktoon van dihidroksikrotonsuur is in 1955 in Afrikaans tetroonsuur genoem, maar is in 1968 tot tetronsuur verdoop.
Die laktoon het egter naas die enolvorm ook nog ' $n$ isomeriese ketostruktuur, wat toe as motivering vir die korrektheid van -oon-in die naam kon gedien het. Die isomerieverskynsel en 'n moontlike ketokarakter vir die verbinding is egter nie op die spel wanneer volgens die voorgestelde nuwe reëls beslis word dat tetroonsuur in elk geval geskryf moet word nie.

* Cationic acid, protonic acid en propionic acid: Omdat cation in Afrikaans met katioon vertaal word en omdat die klem by ioon op die slotlettergreep val, vereis die voorgestelde reëls dat in Afrikaans katioonsuur geskryf sal word. By proton word die klem in Afrikaans egter op die eerste lettergreep geplaas en derhalwe sal protonsuur volgens die nuwe reëls die korrekte vorm wees. Met sy beklemtoonde middellettergreep behoort dus ook propioonsuur geskryf te word - soos dit in 1955 was - en nie propionsuur nie - soos dit sedert 1968 bekend gestaan het.

* Crotonic acid: Hoewel die meeste studente geleer word om die slotlettergreep van kroton te beklemtoon, behoort die klem op die eerste lettergreep te val. Die spelling krotonsuur sal dan steeds die korrekte bly (soos protonsuur).

\section{LITERATUURVERWYSINGS}

1. De Vries, L. \& Kolb, H. (1972). Dictionary of chemistry and chemical engineering. Vol. 2. (Verlag Chemie GmbH, Weinheim; Academic Press, New York and London).

2. Louw, D.F. (1983). Skryfprobleme met chemieterme. 2. Die uitgang -al of -aal in Afrikaans, S.Afr. Tvdskr. Natuurwet. Tegnol., 3, 65-66.

3. Louw, D.F. (1980). Chemieterme met -on en -oon, Die Taalpraktisyn, no. 3, 43-46. 